\title{
A Data-Driven Conceptual Framework for Climate Adaptive Building Shell: A Hybrid Control Strategy
}

\author{
Erhan Karakoç ${ }^{1, *}$, Gülen Çağdaş ${ }^{1,2}$ \\ ${ }^{1}$ Department of Architectural Design Computing, Graduate School of Science and Technology, İstanbul Technical University, 34496, \\ İstanbul, Turkey \\ ${ }^{2}$ Department of Architecture, Faculty of Architecture, İstanbul Technical University, 34367, İstanbul Turkey
}

Received December 21, 2020; Revised February 19, 2021; Accepted March 12, 2021

\section{Cite This Paper in the following Citation Styles}

(a): [1] Erhan Karakoç, Gülen Çağdaş, "A Data-Driven Conceptual Framework for Climate Adaptive Building Shell: A Hybrid Control Strategy," Civil Engineering and Architecture, Vol. 9, No. 2, pp. 427-438, 2021. DOI: 10.13189/cea.2021.090216.

(b): Erhan Karakoç, Gülen Çağdaş (2021). A Data-Driven Conceptual Framework for Climate Adaptive Building Shell: A Hybrid Control Strategy. Civil Engineering and Architecture, 9(2), 427-438. DOI: 10.13189/cea.2021.090216.

Copyright $\bigcirc 2021$ by authors, all rights reserved. Authors agree that this article remains permanently open access under the terms of the Creative Commons Attribution License 4.0 International License

\begin{abstract}
Climate adaptive building shells contribute to improving building energy performance and occupant's comfort needs by using control strategies. Climate adaptive building shells carry out the adaptation efficiently thanks to the mechanisms consisting of sensors, processors and actuators systematically participated in decision-making process. In this article, it is aimed to examine the strategies that contribute to the efficient operation of the elements and components controlled by the strategies in the context of climate adaptive buildings. In addition, it is aimed to develop a conceptual framework of hybrid control strategy based on measured data, weather forecast data and received data based on time pattern. The methodology of this paper is to review existing literature on climate adaptive building shells and adaptation mechanism via developing a conceptual framework for a hybrid control strategy for occupant's comfort and energy efficiency. It is structured to provide a framework for examining design and management principles and their relationships between elements and components. The contribution of this study is to evaluate the design and potentials of the adaptation mechanisms and control strategies in the context of climate adaptive architecture. By using more efficient control systems and mechanism, sustainability related to energy conservation of the building can be enhanced.
\end{abstract}

Keywords Climate Adaptive Building Shell, Conceptual Framework, Hybrid Control Strategy, Data-Driven Design

\section{Introduction}

An occupant-centered contemporary design approach that contributes to sustainability is described as adaptive architecture. [1-4]. This approach can be handled from different perspectives such as adaptation scales [1,5], climate adaptation [5-8], and adaptability [9,10]. The widely discussed area of adaptive architecture can be described as climate adaptive buildings and its shells $[5,8,11]$.

Adaptive building shell is a building layer that plays a distinctive role between the exterior and interior space and aids to provide ideal comfort conditions for occupants by ensuring the energy conservation of the building $[2,12]$ as a contribution to sustainability of built environment. Climate adaptive building shells (CABS) allow buildings to be responsive and react efficiently to environmental stimuli according to existing and predicted conditions $[13,14]$.

CABS, which can respond according to environmental and climatic factors, increase occupants' comfort, ensure the building is performative, reduce the operating costs of the building, and can be seen as an important solution to prolong the life of the components of the building $[15,16]$. In all these aspects, it can be argued that they have advantages compared to static building shells $[13,16,17]$.

In addition to this, Hasselaar [18] stated that the CABS should differ from static building shell in a way that CABS can adapt their components and mediate between the changing climatic conditions. Moreover, CABS must 
response accurately to the effects of environmental and climatic changes to provide comfort requirements such as heat, light, humidity, rain, solar radiation, noise $[19,20]$. CABS provide optimum conditions for occupant by effectively responding to the changing climatic factors appropriately $[21,22]$. In addition, CABS enables the building to save energy by adapting to the current weather conditions, responding instantly to functional needs and occupants' preferences to ensure indoor comfort $[1,23]$. They are generally defined as multi-functional smart systems that separate indoor and outdoor that can adapt their components' behavior over time according to the functional requirements and special conditions [1,20].

Nowadays, CABS are becoming more and more important due to correspondingly changing environmental and climatic conditions. Adaptive building shells must be able to respond to changes in boundary conditions continuously and in accordance with the requirements of the effect, by acting as a whole with the structure, that is, in an integrated manner, according to performance requirements and motivations [24].

CABS are a performative building layer separating the interior and exterior environments, where decision-making systems, smart materials, innovative building details are used and technological approaches are embedded [25-29].

Moreover, CABS provide actuation according to input via control systems including processors, sensors and actuators that aim to provide occupant comfort conditions as a performative way. This article has been structured to examine these control systems and their relationships between elements and components and to provide a framework for developing a hybrid control system.

Within the scope of the article, it is aimed to investigate the design principles and control strategies of CABS. Also, the ways that can be followed for these control strategies and components to work in an integrated manner. As a result of this, various predictions are made about the alternative control strategies required by CABS. The original scientific contribution of this study is three-fold. The first one is a conceptual framework for CABS and an evaluation of the elements and components of the CABS. Secondly, it is determined to analyze the relationship between the design strategies of CABS and control strategies based on weather forecast data and received data based on time pattern. Thirdly, the conflicts that arise because of the control strategies of CABS are highlighted and hybrid control strategy is proposed as an alternative strategy to solve these conflicts in decision-making.

\section{Background}

Climate adaptive building shells can be defined as the building layer that plays a prominent role between indoor and outdoor by providing comfort conditions by using active and passive systems $[5,8,30]$. Active systems such as heating, ventilation, and air conditioning systems are used more than passive systems in providing comfort parameters of interiors [31,32]. However, active systems are not viable due to the operating costs and not contributing to the sustainability of buildings. In response to the disadvantages of active systems, innovative and performative building elements and CABS components controlled by various control strategies and intelligent systems are proposed as a solution [26,29,30].

CABS react to the needs and preferences of occupants, exterior or interior environment [33]. Their reaction varies according to the situation for which they are built. When CABS are designed, stimulus can be selected as occupants to which the building adapts. As a result of this design, occupants can have the authority to change and differentiate response of the building shell. At the same time, the building shell can automatically respond to them in a specific way, or it can recognize the occupant and change its response accordingly [21]. Moreover, the multi-person participation is the most prominent part of designing building shell that responds to the occupants depending on the interaction capabilities of the system [34]. In this case, it should be planned on which the building responds and how this respond occurs [22]. Improving the comfort conditions, evaluating the indoor and outdoor climatic and environmental changes, and designing buildings that react to these changes can be observed as the motivations of the preferability of CABS $[11,30]$.

\subsection{Elements of CABS}

While adapting to the changes, buildings make use of adaptation elements ensuring that the building is adaptive at different levels. Either all elements or a single element is adaptive in a building can be found as different design approaches in the literature $[35,36]$. In the literature, the adaptation mechanisms are classified as two kinds. The first is mechanical adaptation that is defined as the change in the appearance and general properties of the architectural surface by mechanically changing its components [37]. Hydraulic and pneumatic adaptations are also examined under mechanical adaptations. Apart from mechanical adaptation, secondly, the adaptation of surface elements using display or lighting technologies comes to the fore. Lighting and display technologies are considered as an alternative method for adapting surface elements. Although this adaptation is complementary to an adaptation or an interaction in some cases, it cannot go beyond a visual change in some cases [38].

Adaptation elements can be categorized as components and technical systems. Components are the parts that form either the whole building shell to provide to adaptation of the shell [16] such as structural system, surface and mechanism or smaller scale parts that can be adaptive [39]. To ensure that the building shells are adaptive, some 
components need to be designed and placed as variable and flexible $[1,7,8]$. The adaptation of the components of the buildings directly affects the spatial properties and enables the space to adapt to both changing conditions and climatic conditions. Technical systems enable the building to adapt to changing conditions with the sensors and actuators [29]. By working together with other electronic, mechanical, or electromechanical systems and building infrastructure such as heating, ventilation, and air conditioning systems they enable the occupant to be in more comfortable environments $[5,33]$. These systems can be considered as a part of automation as well as forming the backbone of climatic adaptation.

\subsection{Components and Mechanism of CABS}

The adaptation process varies according to different adaptability levels determined by the number of adaptive components controlled by sensors, processors, and actuators according to input. The input is required to activate the components to respond change in occupant preferences, environment, and climate and energy performance. According to Kronenburg [40], inputs can also change according to the interaction type of buildings in transformable dynamic designs. It does not seem possible to directly classify the inputs because the interaction methods differ according to the design. However, the data sources, which are widely used are mechanical inputs and digital inputs, i.e., data.

Mechanical inputs vary according to the direction, severity, and type of the stimulus. Adaptation is designed as systems where physical effects such as pushing, pulling, rotating is transferred to the processor [41]. The use of mechanical inputs is especially common in building shell and interior partitions. An example of this type of input can be the opening and closing of the building shell layers or changing them by rotating as needed. It also exists in nature-inspired approaches used in adaptive shells that change through pressure $[42,43]$. There are architectural elements that act by taking advantage of varying amounts of pressure, such as turgor pressure in plants. For this reason, the mechanical stimulus differs according to the design and is re-evaluated accordingly [44].

Digital inputs have become widespread in buildings, especially due to the development of digital technologies such as sensor technologies and the measurement elements. The data that provide adaptation in buildings are obtained with the help of advanced sensors that are precise. Just as people use sensory organs such as vision, hearing and feeling to perceive outside, they are used in buildings to detect the data in their environment with the advanced sensors.

The response initiated by input determines the classification of adaptive buildings can be different [11]. If the response of the shell is affected by the mechanical or digital interaction of occupants, it is defined as interactive architecture classified under adaptive buildings $[45,46]$. Environmental effects and changes are considered as inputs in the responsive architectural shell [27]. In kinetic building shell, a mechanical input can activate the movement of the building shell such as pushing, pulling, rotation, etc. Therefore, outputs in kinetic buildings are generally mechanical [47]. In intelligent buildings, inputs are mainly the data that are collected via mainly sensors [48] and are analyzed digitally [49] to feed the control system.

Sensors such as proximity and distance sensors such as Kinect and Wii, light sensors, temperature sensors, air quality measurement sensors, humidity sensors and precipitation sensors are considered as the main data sources [25] by which environmental information and interactions with occupants can be detected $[48,50]$. These data are considered as quantitative sources that guide adaptation and response.

The data from the sensors are evaluated by the processors. Processors ensure that the response with actuators that should be given according to the inputs $[26,30]$. Processors decide how the response $[48,51]$ will be and with what architectural element. Processors handle the input they receive and transmit it to the actuators by determining the degree of the response. Processors can evaluate mechanical inputs as well as digital inputs. They can make complex analyzes, inferences, and judgements. In addition, processors can be interpreted as a mechanism designed to generate the programmed response and adaptation. Processors behave like the human brain [48]. In this way, they form the most important point of the CABS mechanism designed for data processing. They are usually managed through software. In this way, they determine what kind of order they will send to the actuators by evaluating the inputs.

They perform this management by interpreting the data through mechanisms that can differ according to the complexity level of the algorithm or software. In some cases, these processors can actively take part in tasks such as increasing comfort conditions and managing building shells through the building management system. They can be programmed by various optimizations using multiple data or variable data with complex algorithm or software [52]. In this way, they control the actuators and help them work in an adaptive way. Processors can be directly related to inputs especially in mechanical processes. Processors handle mechanical inputs by increasing and decreasing their effect and changing their type. While doing this, they use mechanical transfer methods. In mechanical transmissions, gears, shafts, riveted surfaces, and similar mechanical tools can be used [53] In these transfers, the mechanism of action must be mechanically differentiated.

Actuators form the last step of the reaction mechanism. They ensure that orders from processors are executed correctly. These orders can be mechanical and digital. The 
actuators, on the other hand, follow the order from the processors and make the digital or mechanical input visible by adapting the elements. Whether the actuators are active or de-active is fed back to the processors after the respond is given. Therefore, there is either an alternating or direct relationship between inputs, processors, and actuators [52,54].

Mechanical responses can transmit their responses to actuators, without any algorithm or software, only by means of some mechanical rules and these transfers are again mechanical [51]. Mechanical systems and physical stimuli are used in all manual adaptation methods. In this way, it takes place mechanically in the final stage. Non-mechanical digital adaptations in buildings depend on various actuators to achieve the intended responses. Lighting [55], ventilation, air conditioning control [56], servo and stepper motors [5,57], hydraulic and pneumatic actuators [6,58] and various media screens [59] can be shown as examples of actuators in this scope [37]. Actuators are very critical in providing comfort conditions and creating various effects. Actuators allow or help building shells to move, and buildings can thus conserve energy.

\subsection{Design and Management Strategies in CABS}

CABS have different design strategies. They are designed to ensure sustainability and increase interaction with the environment and adapt to special climatic conditions $[20,45]$. In order to look more accurately at the issue, certain general techniques in adaptive architecture should be highlighted.

The prominent feature of CABS is to be dynamic. Buildings must be dynamic to adapt to and be in harmony with environmental changes $[1,8,26]$. Therefore, dynamic, and kinetic building shells frequently appear in the adaptive architecture literature. The whole shell may be dynamically constructed, or an element or a building shell part [60]. Considering its dynamic nature, the CABS can respond to stimuli and create a performative structure $[16,17,30]$.

Another important CABS design strategy is to conceptualize it to meet the necessary needs during the building life cycle. Therefore, even though the occupant varies, the shell activities of the building should conform to the occupant's comfort conditions [61]. By keeping future needs for convenience into consideration and predicting weather patterns, CABS should be conceptualized. This strategy paves the way for the building to lead to its sustainability and be permanent [62]. Moreover, CABS may adapt in the short-term or long term i.e., seconds to seasons $[5,8]$.

CABS should be designed and constructed such that the comfort of the occupant is in accordance with their environments [49]. Adaptive buildings sense the changes in parameters such as temperature, humidity, light level around them with the help of sensors located indoors and outdoors, and allow the CABS to act appropriately to bring these parameters to the level determined comfortably for the occupant [22]. Also, CABS should be conceptualized to provide an interaction with the occupant to check whether conditions the response is accurate $[5,33]$.

Finally, manual, or automatic compatibility with many electronic, mechanical, electromechanical, or mechatronic, pneumatic, hydraulic, and similar systems has significant place in the CABS design process [6,37]. CABS should be designed in such a way that it can react effectively to the conditions of energy savings and occupant comfort through its control systems. They are responsible for analyzing the data required for the management of the CABS and providing the appropriate response to meet the criteria that are positive for the building and the needs specified by the occupant.

Building control system types are divided into two such as extrinsic and intrinsic [8]. Sensors, processors, and actuators are used in extrinsic control strategies to make decisions and respond. Owing to feedback mechanism of extrinsic control systems, the CABS can measure the consequences of its own decision and make revisions in the decisions it conveys to the actuator when necessary, allowing the building shell to adapt again. Extrinsic control systems are divided as centralized and distributed $[5,8]$. In centralized control system, all operating systems and control systems are connected to a single structure and hierarchy called the "brain" [48]. This hierarchy evaluates the whole components and makes the decision accordingly [62]. While centralized systems are advantageous in terms of collecting processors in a single center, they are disadvantageous in solving some partial and regional problems. Distributed systems can be defined as embedded systems that process data by evaluating individual or modular processors' own decisions. The decision made in distributed systems allows regional response by enabling only the unit in that region to be activated by the actuators $[8,63]$. These systems are more difficult to integrate into the building automation system than centralized systems. However, they can give faster and more effective response to multi occupant and variable climatic conditions in specific regions. Intrinsic control strategies can be described as climate adaptive design strategy that contain inherent potentials. The CABS that are controlled intrinsically respond according to the humidity, temperature, and air quality. The responses in intrinsic design strategies are often provided by smart and adaptive materials $[8,48]$.

\subsection{Conflicts in the Decision-making of CABS}

Control systems of CABS have a decision-making mechanism that enables optimization of more than single parameter by using hierarchy. Thanks to this mechanism, the building shell works efficiently by aiming accurate decisions. The building shell control system optimizes according to multiple parameters and manages the components with the help of advanced algorithms [64]. 
However, many parameters can be mutually contradictory and could cause conflicts. Energy efficiency of the building can be decreased due to these conflicts $[5,65,66]$. In the CABS, there are two main reasons of the conflict between parameters of design. One of the conflicts is caused by occupant's demand of different condition parameter levels. The other conflict occurs between occupants and control algorithms [50]. Besides, problems may occur by conflicting climatic parameters such as temperature, light level, humidity level, air quality etc. due building energy performance. Thanks to the hybrid control strategy developed within the scope of this article, a hierarchy of decision-making system designed to increase both occupant comfort conditions and building performance is proposed.

The original scientific contribution of this article to literature is the conflict solving algorithms that are named hybrid control strategy based on weather forecast data and received data the day before comparatively with measured data. The extensive research in recent climate adaptive control strategies shows that the main data for the decision-making system is ambient data as input. Thus, the conflict encountered in the boundary conditions of decision-making systems is solved with an alternative control strategy called hybrid.

\section{A Conceptual Framework for Hybrid Control Strategy}

CABS and control strategies have been developing in parallel to the advances in various areas of the technology. The development of sensor technologies has enabled the building to measure inputs more accurately. Due to the more efficient work of the motorized, hydraulic, and pneumatic systems enabled actuators to react more accurately and precisely. The development of microprocessors, chipsets, databases, and micro disks has also enabled control strategies to work more efficiently.
These developments in hardware have been supported by software and data-driven systems. The design of advanced and complex algorithms differing in software further increases the efficiency and functionality of CABS. Inputs, processing factors, control strategies and actuators have the significant effect on working principle of CABS.

In the control strategies of CABS, climatic parameters are temperature, light, humidity, and environmental parameters such as air quality (Figure 1). Inputs are controlled by considering various processing factors mainly the occupant's and environmental needs. The occupant may have demands that vary based on comfort needs and building function. Another processing factor can be summarized as energy effectiveness and performative needs. This factor is important in terms of providing energy conservation and efficient operation of the CABS. Apart from the needs of the occupant and environmental, there are many other factors such as building investment budget, sociological issues and building design regulations. Since building investment budget, sociological issues and building design regulations are relatively less important than occupant and environmental needs, they are excluded from the scope of this study.

Many different numbers of strategies in building control systems found in the literature [5$7,24,26,30,43,48,49,51,66-69]$ have been identified such as occupants needs, climatic conditions and building function, the existing strategies, which can be summarized as 3 different strategies (Figure 1). The first of these strategies is the conventional control strategy in which climatic data are received through sensors and the required response is given instantly. Reasoning is not very advanced on these systems due the instant response. Responses constructed according to certain parameters become visible through actuators. The building shells where this strategy is applied are usually designed to evaluate and react to two or fewer stimuli.
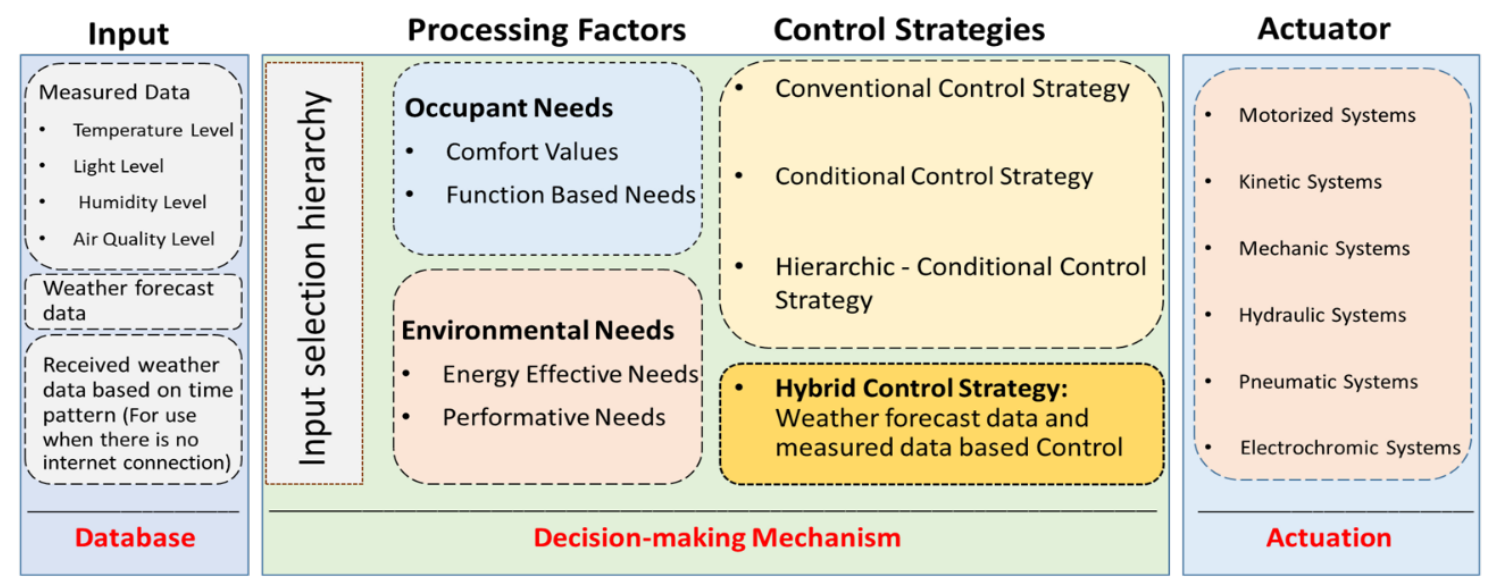

Figure 1. Input, processing factors, control strategies and actuators of CABS 
The second type of control strategy is called the conditional control strategy. In this strategy, non-complex conditional algorithms are used to process the received data. The results of the reaction generated because of these algorithms are not measured and the feedback mechanism is poorly executed.

The third type of control strategy is called the hierarchic-conditional control strategy. In this control strategy, the data received are carried out with complex algorithms. These algorithms process the received data and make the actuator according to response hierarchy. As a result of this movement of the actuator, the comfort parameters that occur indoors and outdoors are measured, and feedback is provided to the decision-making mechanism. In these systems, centralized and distributed systems can be used in an integrated manner with each other. At the same time, they can use passive and active system synchronized by working with each building automation system as the decision-making phase of these systems. In this control strategy, there are parameters that take priority in the decision-making hierarchy that is carried out according to this priority order. However, in some cases, conflicts in various comfort conditions can occur in which the module only reacts in accordance with the designed algorithm while making its decision.

The hybrid control strategy developed within the scope of this article is a control strategy that can be described as the fourth type (Figure 1 and Figure 2). Unlike the hierarchic-conditional strategy, this module executes an argument by using weather forecast data or a received data of the day before.

The execution of the algorithm depends on two conditions. If the brain of the CABS can reach internet connection, decision making mechanism process the measured data and weather forecast data from internet by comparing with the data at that time. Next, the decision can be made accurately not only for the time on the measurement also for the time interval after a while. By using weather forecast data based on internet, decision-making mechanisms organize the actuation mechanism for an hour, two hours, or a day. If there is no internet connection, the decision-making mechanism follows the second path.

The decision-making mechanism works according to time pattern (such as sun set and sun rise) for boundary situations. Also, the received data of the day before can be processed by the decision-making systems to reach ideal movement of CABS (Figure 2). Depending on this process of reasoning, the control system does not only analyze the instant data received from the sensors, but also analyzes weather forecast data (with internet) the data belonging to the same time of the day before (with no internet) to organize its response. It measures the results of the response by checking the accuracy of previous actuations with the embedded feedback mechanism.

Actuators are the elements that allow movement to take place and make this movement visible in the CABS. Actuators can be differentiated according to the needs of the building. The design of the building shells to contain different layers or mechanisms that react to different effects and the good analysis of the relationship between actuators and control strategies have a great contribution to the performative efficiency of the building.

Following section describes the conceptual framework of a hybrid strategy based on weather forecast data and saved data based on time pattern as complementary data set as an original scientific contribution to the literature. It is aimed to discuss the three control strategies in the literature and the proposed hybrid control strategy as a response the limitations of the control strategies. Conceptual framework and mechanism of the hybrid control strategy, which is an alternative control strategy, is explained and evaluated by comparing to the mentioned control strategies in the background section.

\subsection{A Hybrid Decision-making Process}

In the literature, two main reasons are explained for the conflicts of design strategies of the CABS [5]. These needs may conflict with each other in the various needs listed under these headings. For example, the temperature targeted by the occupant as the ideal temperature can increase the operating costs of the CABS and may conflict with environmental needs. Besides, it can be exemplified as the conflict between the need for opening the shells of the building to provide clean air acquired by the occupant repetitively and the avoidance of over-actuation of the shell due to the material fatigue shortening the life of the building. In another case, it is possible that there is a conflict with environmental needs due to the direct reactions of the shell. For example, in cases where there is a high difference in temperature levels and light levels such as sunset and sunrise especially in the Mediterranean climate or Semi-arid climates, the building can give sudden responses and make conflicting decisions. These decisions cause both shortening of building life and operating costs.

The proposed alternative control strategy consists of a series of decision-making mechanisms used for the optimization of conflicting parameters based on weather forecast data and received data. In this decision-making mechanism, occupant comfort conditions are determined as the high priority target to be met. (Figure 2). The secondary target is determined as energy conservation. In case of small deviations that are out of the value range of activation but not noticed by the occupant, the control strategy is activated again and provides energy conservation. In this system, minimizing the actuators' movement is designed as another feature of the alternative strategy. It is predicted that the hybrid control strategy, in which these principles are observed, will contribute to efficiency of CABS in the industry. 


\subsection{The Evaluation of the Hybrid Control Strategy and Further Research}

In the hybrid control strategy, inputs are determined as environmental factors such as temperature level, light level, humidity level and air quality. Certain value ranges of environmental factors have been described as suitable for the comfort needs of the occupant. Thanks to the hybrid control strategy, if the occupants comfort needs are in the specified range, then it is investigated whether there is an internet connection. In the continuation of the process, if the system has internet access, then Weather Forecast data obtained from the nearest meteorology station are taken and integrated into the decision-making process. The next question in the hybrid control strategy is whether the current environmental requirements are met. If so, the predictions about whether it will meet the environmental needs for the future are evaluated. When it meets this situation, the actuations are de-activated. If it does not fulfil these conditions for a short time, then the actuators are activated. As stated before, if internet access is not available, the process is continued with the other control strategy that provides optimization for the limit values.

At the same time, a certain amount of deviation has been determined for values outside the range of limiting values. If all inputs measured from the sensors are in the interval value, the building measures the expectation in the next time interval. Here, the input data evaluated by the control system are the climatic pattern of the day before. This contributes to the more effective progression of the control strategy at sunset and sunrise times and sudden value changes. In the process following this control, if a change will occur, it is evaluated whether it is suitable for energy conservation. As a result of this evaluation, if the energy contributes to the conservation, the actuator is de-activated.

If it does not contribute, then the control system decides on the state of the actuator according to the weather of that day and previous day. If the building is not suitable for occupant's comfort conditions, then it is analyzed if the occupant will feel the change in comfort conditions. If the measured values are within the acceptable range under comfort conditions, the actuators are activated. If it is not within the acceptable range, the state of the actuator is decided by evaluating the values of that day and previous day.

Another measurement is to assess whether there is any conflict between control parameters (Figure 2). If there is no conflict between the control parameters, the control system continues the cycle by checking whether the comfort parameters are in the range in which the occupant cannot sense the changes. In the decision-making process, if there is a conflict between parameters, then the decision-making hierarchy is applied. The important question here is which parameter has higher priority over other parameters effecting the occupant's comfort. The input parameter is evaluated in the first stage of the control strategy to be measured again by including in the decision-making process.

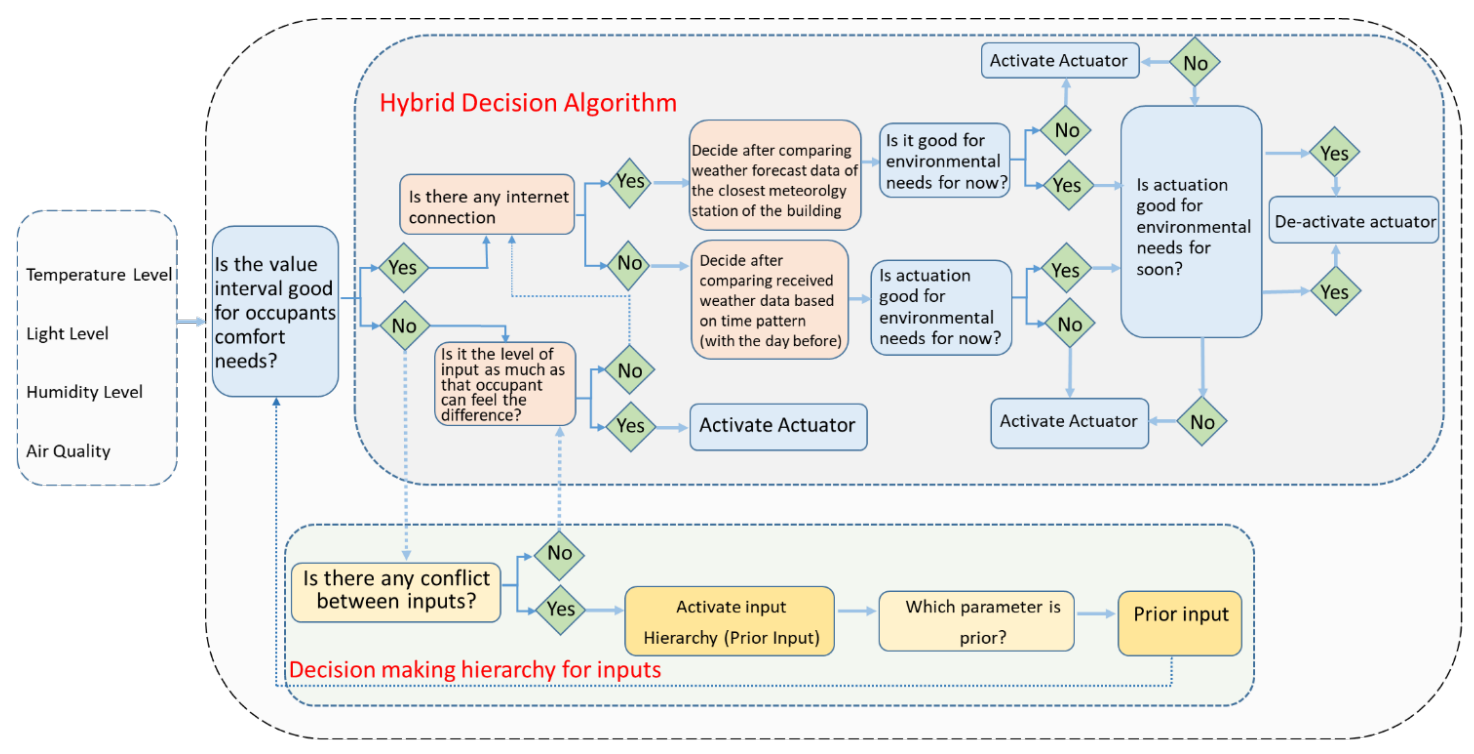

Figure 2. Flowchart of the alternative control strategy and decision-making process 
Table 1. Mechanism and evaluation of the control strategies

\begin{tabular}{|c|c|c|c|}
\hline \multirow{2}{*}{ Control Strategies } & \multirow{2}{*}{ System Mechanism } & \multicolumn{2}{|c|}{ Evaluation of The Control Strategies } \\
\hline & & Advantages & Disadvantages \\
\hline $\begin{array}{c}\text { Conventional Control } \\
\text { Strategy }\end{array}$ & $\begin{array}{ll}\text { - } & \begin{array}{l}\text { Designed for direct } \\
\text { response. }\end{array} \\
\text { - } & \text { If-else algorithm. } \\
\text { No Feedback. } \\
\text { - }\end{array}$ & $\begin{array}{l}\text { Occupants can select their } \\
\text { preferences easily. } \\
\text { Many prototypes in literature and } \\
\text { industry. } \\
\text { - Intrinsic systems can be adapted to } \\
\text { this control strategy (Especially in } \\
\text { the material-based systems). } \\
\text { - Extrinsic systems can be solved with } \\
\text { only one parameter. }\end{array}$ & 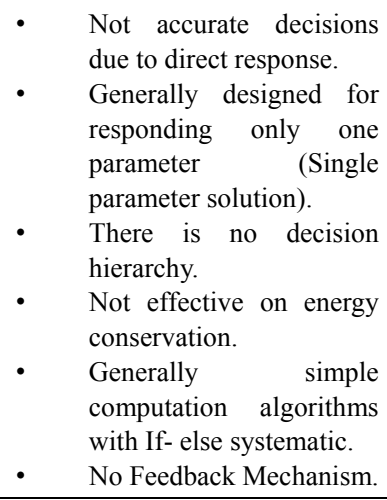 \\
\hline $\begin{array}{c}\text { Conditional Control } \\
\text { Strategy }\end{array}$ & $\begin{array}{ll}\text { - } & \text { Designed for } \\
\text { conditional-response. } \\
\text { - } \\
\text { If-else algorithms more } \\
\text { than a layer. } \\
\text { - Limited-Multi-object } \\
\text { Algorithm } \\
\text { - Limited Feedback. } \\
\text { Limited Decision-Making } \\
\text { hierarchy. } \\
\text { Manual and Automatic } \\
\text { options. }\end{array}$ & 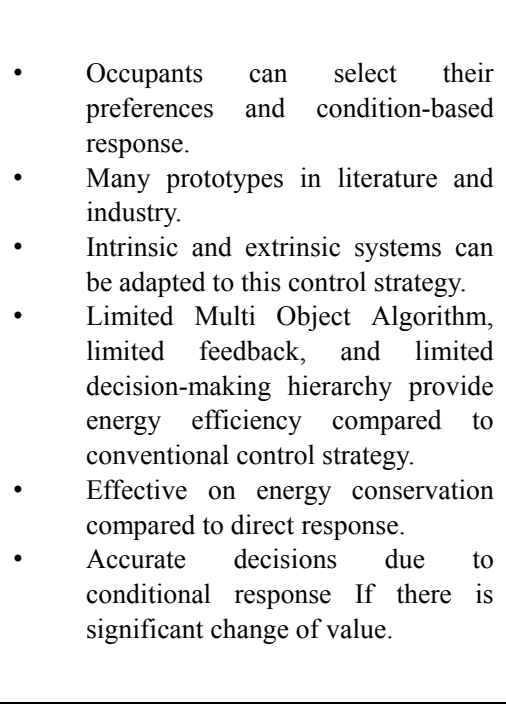 & $\begin{array}{l}\text { - Generally designed for } \\
\text { responding less than three } \\
\text { parameters. } \\
\text { Limited hierarchy does } \\
\text { not work accurately all } \\
\text { the time. } \\
\text { Limited Feedback } \\
\text { Mechanism does not } \\
\text { provide optimum } \\
\text { occupants' comfort. } \\
\text { No prediction, or } \\
\text { day-time season-time } \\
\text { condition orientation. } \\
\text { Not effective on energy } \\
\text { conservation on private } \\
\text { times such as sun rise and } \\
\text { sun set. } \\
\text { No prediction of } \\
\text { precipitation and sudden } \\
\text { input value changes. }\end{array}$ \\
\hline $\begin{array}{l}\text { Hierarchic-Conditional } \\
\text { Control Strategy }\end{array}$ & $\begin{array}{ll}\text { - } & \text { Designed for Hierarchic } \\
\text { conditional-response. } \\
\text { Hierarchy Based control } \\
\text { algorithms. } \\
\text { - } \quad \text { Multi-object Algorithm. } \\
\text { - } \quad \text { Priority Algorithms. } \\
\text { Feedback and feedback on } \\
\text { loop. } \\
\text { Decision-making } \\
\text { hierarchy for selected } \\
\text { multi parameters. } \\
\text { Manual and Automatic } \\
\text { using options. }\end{array}$ & $\begin{array}{l}\text { Occupants can select their } \\
\text { preferences and energy conservation } \\
\text { plans. } \\
\text { Intrinsic and extrinsic systems and } \\
\text { building automation can be adapted } \\
\text { to this control strategy. } \\
\text { Multi Object Algorithm, feedback, } \\
\text { and decision-making hierarchy } \\
\text { provide energy efficiency compared } \\
\text { to Conditional control strategy. } \\
\text { Effective on energy conservation } \\
\text { compared to conditional response. } \\
\text { Feedback Mechanism helps } \\
\text { occupants' comfort. } \\
\text { More Accurate decisions due to } \\
\text { conditional response. }\end{array}$ & 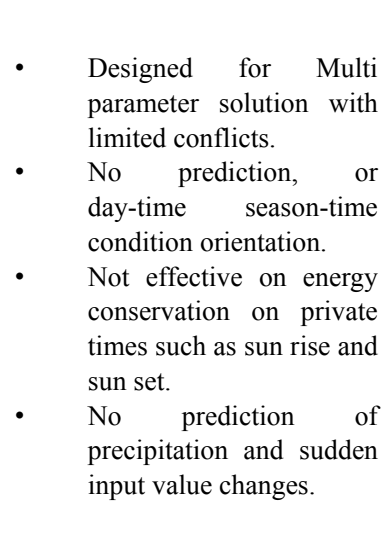 \\
\hline
\end{tabular}




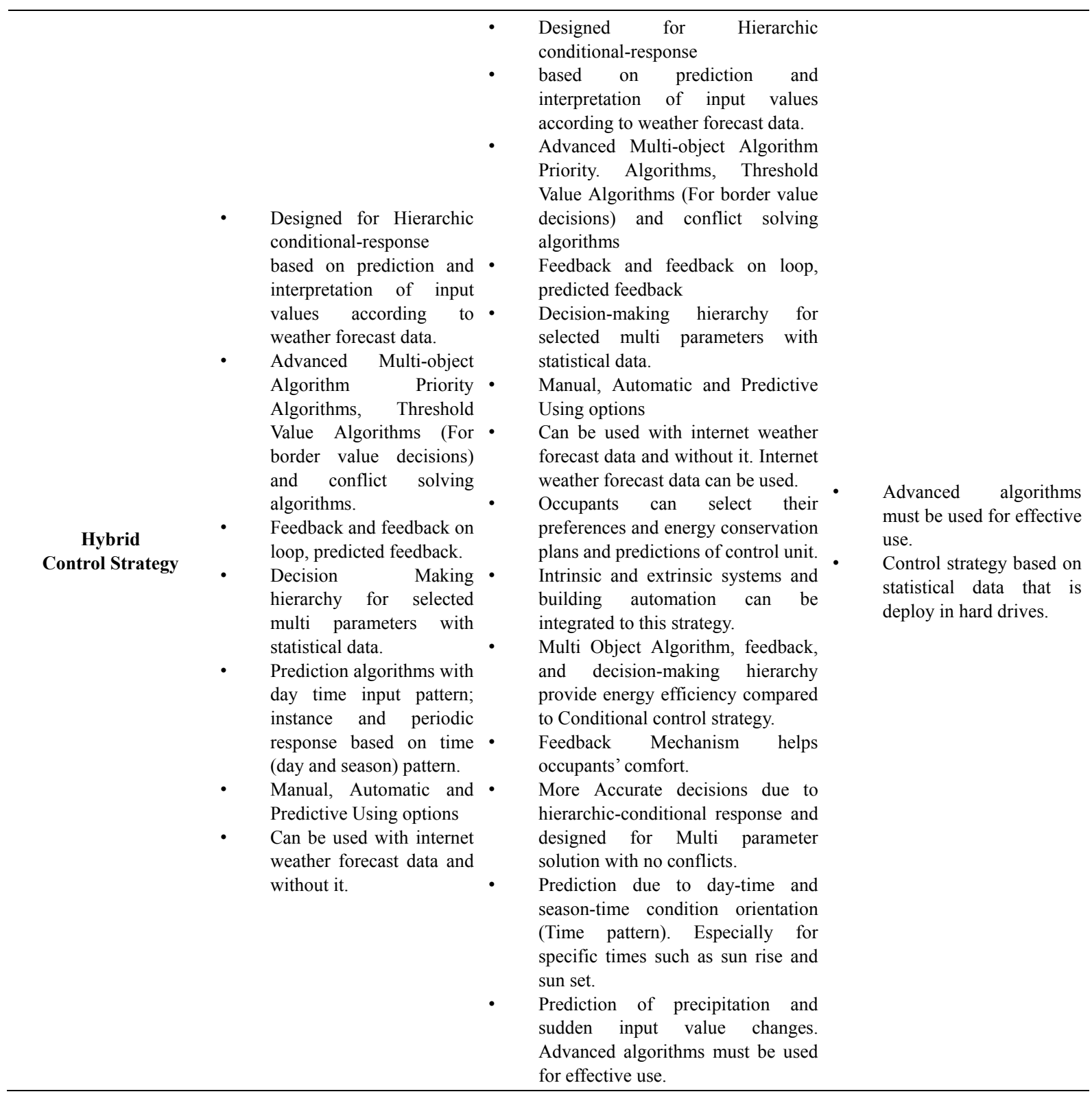

Adaptive building shell control systems have a decision-making mechanism that allows multiple parameters to be optimized by weather forecast data and received data. The control system optimizes multiple parameters and manages the CABS with the proposed hybrid strategy and flowchart (Figure 2). In this section, it is aimed to discuss the advantages and disadvantages of the control strategies by comparing the proposed control strategy and existing strategies (Table 1).

According to the evaluation discussed in Table 1, the alternative control strategy called hybrid is thought to be more effective than the other three strategies. It is anticipated that this control strategy will be preferable because of the parameter selected by the occupant is firstly evaluated. This strategy is also relatively advantageous in terms of minimizing the actuators' movements and preventing material fatigue on the building shell. In addition, using the weather forecast data sourced from internet is important for making decisions for not only that moment, also for the future time pattern. Moreover, in the situations that internet is not on, by analyzing the pattern of the previous day and making decisions by predicting the specific times such as sunset and sunrise contribute to building energy conservation. According to all these evaluations, the hybrid control strategy is considered as an efficient and performative alternative to the other three control strategies.

In future studies, it is intended that a prototype which consists of sensors and actuators controlled by proposed alternative control system are built and monitored. 


\section{Conclusions}

CABS are building layers that increase energy efficiency by providing limited interaction with outdoor conditions. In addition, adaptive building shells using optimization-oriented decision-making systems, smart materials, innovative details, and other technological approaches contribute to the sustainability of buildings [5-7,11,19,30,33,34,56,63,67,68,70,71]. Potential application areas of adaptive building shells have been developing in parallel with technological developments such as control and decision-making systems $[5,48,49,51,52,54,69]$.

CABS is the occupant centric approach focused on energy conservation and performance. Also, the elements and components of these CABS parts are discussed by the authors in the context of the adaptation mechanism. Moreover, the control strategies that play a key role in the controlling and decision-making of CABS is examined. As a result of these investigations, a hybrid control strategy designed by the authors as an original contribution to the literature is put forward. The conceptual framework and mechanism of the control strategy, which we call hybrid is described in this article. Also, this strategy is evaluated, and mechanisms are compared. In addition, advantages and disadvantages are compared to other control strategies according to parameters such as occupant comfort, energy conservation and material fatigue.

Decision-making mechanisms are systems where various algorithmic, automated, and computational systems are used together for adaptive building shells to be efficient. Mechanisms capable of working as human intelligence in terms of analysis will be able to better anticipate occupants' comfort with the further development of the use of fuzzy logic, machine learning, deep learning, neural networks, and other artificial intelligence algorithms.

\section{REFERENCES}

[1] Loonen, R. C.G.M; Rico-Martinez, J.M.; Favoino, F.; Brzezicki, M.; Menezo, C.; La Ferla, G.; Aelenei, L. Design for Façade Adaptability-Towards a Unified and Systematic Characterization. In Proceedings of the Proc. 10th Energy Forum-Advanced Building Skins, Bern, Switzerland; 2015; pp. $1274-84$.

[2] Aelenei, D.; Aelenei, L.; Vieira, C.P. Adaptive Façade: Concept, Applications, Research Questions. Energy Procedia 2016, 91, 269-275, doi: 10.1016/j.egypro.2016.06 .218 .

[3] Biloria, N.; Sumini, V. Performative Building Skin Systems: A Morphogenomic Approach towards Developing Real-Time Adaptive Building Skin Systems. International Journal of Architectural Computing 2009, 7, 643-675, doi:10.1260/1478-0771.7.4.643.

[4] Loonen, R.C.G.M.; Favoino, F.; Hensen, J.L.M.; Overend, M. Review of Current Status, Requirements and Opportunities for Building Performance Simulation of Adaptive Facades. Journal of Building Performance Simulation 2017, 10, 205-223, doi:10.1080/19401493.2016 .1152303 .

[5] Karakoç, E.; Çağdaş, G. Adaptive Architecture Based on Environmental Performance: An Advanced Intelligent Façade (AIF) Module. Gazi University Journal of Science 2021, doi:10.35378/ gujs.725902.

[6] Karakoç, E.; Çağdaş, G. Performative Architecture with an Adaptive Building Façade. In Proceedings of 18th Generative Art Conference, Venice, Italy; 2015.

[7] Attia, S.; Lioure, R.; Declaude, Q. Future Trends and Main Concepts of Adaptive Facade Systems. Energy Science and Engineering 2020, 8, 3255-3272, doi:10.1002/ese3.725.

[8] Loonen, R.C.G.M.; Trčka, M.; Cóstola, D.; Hensen, J.L.M. Climate Adaptive Building Shells: State-of-the-Art and Future Challenges. Renewable and Sustainable Energy Reviews 2013, 25, 483-493, doi: 10.1016/j.rser.2013.04.01 6

[9] Güzelci, O.Z.; Alaçam, S.; Kocabay, S.; Akkuyu, E.I. Adaptability of Primary and Middle Schools to Post-Pandemic Reuse - A Discussion in the Context of Flexibility; Journal of Design Studio, 2020. doi: $10.46474 /$ jds. 776665

[10] Güzelci, O.Z.; Şen Bayram, A.K.; Alaçam, S.; Güzelci, H.; Akkuyu, E.I.; Şencan, I. Design Tactics for Enhancing the Adaptability of Primary and Middle Schools to the New Needs of Post-Pandemic Reuse. Archnet-IJAR 2020, doi:10.1108/ARCH-10-2020-0237.

[11] Romano, R.; Aelenei, L.; Aelenei, D.; Mazzucchelli, E.S. What Is an Adaptive Façade? Analysis of Recent Terms and Definitions from an International Perspective. Journal of Facade Design and Engineering 2018, 65-76 Pages, doi:10.7480/JFDE.2018.3.2478.

[12] Attia, S.; Garat, S.; Cools, M. Development and Validation of a Survey for Well-Being and Interaction Assessment by Occupants in Office Buildings with Adaptive Facades. Building and Environment 2019, 157, 268-276, doi: 10.1016/j.buildenv.2019.04.054.

[13] Johnsen, K.; Winther, F.V. Dynamic Facades, the Smart Way of Meeting the Energy Requirements. Energy Procedia 2015, 78, 1568-1573, doi: 10.1016/j.egypro.2015.11.210.

[14] Foged, I.W.; Kirkegaard, P.H. Adaptive Architectural Envelope. In Proceedings of the EnergyForum - Solar Building Skins; Economic Forum, 2010; pp. 105-113.

[15] Borg, S.P.; Farrugia, E.; Buhagiar, V. A Comparative Study of the Energetic Performance of Climate Adaptive Façades Compared to Static Façade Design in a Mediterranean Climate. In Proceedings of the 11th Conference on Advanced Building Skins; 2016; pp. 1-10.

[16] Wang, J.; Beltrán; Liliana O. From Static to Kinetic: A Review of Acclimated Kinetic Building Envelopes. In Proceedings of the The Solar Conference; 2012; Vol. 5, pp. 4022-4029. 
[17] Hammad, F.; Abu-Hijleh, B. The Energy Savings Potential of Using Dynamic External Louvers in an Office Building. Energy and Buildings 2010, 42, 1888-1895, doi: 10.1016/j.enbuild.2010.05.024.

[18] Hasselaar, B.L.H. Climate Adaptive Skins: Towards the New Energy-Efficient Façade. In Proceedings of the Management of Natural Resources, Sustainable Development and Ecological Hazards; WIT Press: Bariloche, Argentina, November 22 2006; Vol. I, pp. 351-360.

[19] Attia, S.; Favoino, F.; Loonen, R. C.G.M; Petrovski, A.; Monge-Barrio, A. Adaptive Façades System Assessment: An Initial Review. Advanced building skins 2015, 12651273.

[20] Struck, C.; Almeida, M.; Silva, S.; Mateus, R.; Lemarchand, P.; Petrovski, A.; Rabenseifer, R.; Wansdronk, R.; Wellershoff, F.; Wit, J.D. Adaptive Facade Systems Review of Performance Requirements, Design Approaches, Use Cases and Market Needs. 2015, doi:10.13140/RG.2.1.2023.8165.

[21] Rossi, D.; Nagy, Z.; Schlueter, A. Adaptive Distributed Robotics for Environmental Performance, Occupant Comfort and Architectural Expression. International Journal of Architectural Computing 2012, 10, 341-359, doi:10.1260/1478-0771.10.3.341.

[22] Gupta, S.K.; Atkinson, S.; O’Boyle, I.; Drogo, J.; Kar, K.; Mishra, S.; Wen, J.T. BEES: Real-Time Occupant Feedback and Environmental Learning Framework for Collaborative Thermal Management in Multi-Zone, Multi-Occupant Buildings. Energy and Buildings 2016, 125, 142-152, doi: 10.1016/j.enbuild.2016.04.084.

[23] Attia, S.; Navarro, A.L.; Juaristi, M.; Monge-Barrio, A.; Gosztonyi, S.; Al-Doughmi, Z. Post-Occupancy Evaluation for Adaptive Façades. Journal of Facade Design and Engineering 2018, 1-9 Pages, doi:10.7480/JFDE.2018.3.24 64.

[24] de Boer, B.; Ruijg, G.J.; Loonen, R.C.G.M; Tr, M.; Kornaat, W. Climate Adaptive Building Shells for the Future Optimization with an Inverse Modelling Approach.; Bressanone, Italy, 2013; pp. 15-19.

[25] Kroner, W.M. An Intelligent and Responsive Architecture. Automation in Construction 1997, 6, 381-393, doi:10.1016/S0926-5805(97)00017-4.

[26] Clements-Croome, D. Building Environment, Architecture and People. Intelligent buildings: design, management, and operation 2004, 53-100.

[27] Velikov, K.; Thün, G. Responsive Building Envelopes: Characteristics and Evolving Paradigms. Trubiano, F., Design and Construction of High Performance Homes 2013, 75-92.

[28] Masri, Y. Intelligent Building Envelopes: Design and Applications. In Proceedings of the International Conference on Building Envelope Design and Technology, Graz Advanced Building Skins; 2015; pp. 37-46.

[29] Hayes-Roth, B. An Architecture for Adaptive Intelligent Systems. Artificial Intelligence 1995, 72, 329-365, doi:10.1016/0004-3702(94)00004-K.

[30] Karakoç, E. Intelligent System Design for Environmental
Performance Oriented Adaptive Façade Module, Ph.D. Thesis, İstanbul Technical University, 2021.

[31] Kim, G.; Lim, H.S.; Lim, T.S.; Schaefer, L.; Kim, J.T. Comparative Advantage of an Exterior Shading Device in Thermal Performance for Residential Buildings. Energy and Buildings 2012, 46, 105-111, doi: 10.1016/j.enbuild.2011.1 0.040 .

[32] Freewan, A.A.Y. Impact of External Shading Devices on Thermal and Daylighting Performance of Offices in Hot Climate Regions. Solar Energy 2014, 102, 14-30, doi: 10.1016/j.solener.2014.01.009.

[33] Park, J.Y.; Ouf, M.M.; Günay, B.; Peng, Y.; O’Brien, W.; Kjærgaard, M.B.; Nagy, Z. A Critical Review of Field Implementations of Occupant-Centric Building Controls. Building and Environment 2019, 165, 106351, doi: 10.1016/j.buildenv.2019.106351.

[34] Luna-Navarro, A.; Loonen, R.C.G.M; Attia, S.; Juaristi, M.; Monge-Barrio, A.; Donato, M.; Rabenseifer, R.; Overend, M. Occupant-Adaptive Façade Interaction: Relationships and Conflicts. In Proceedings of the Facade 2018-Adaptive! Proceedings of the COST Action TU1403 Adaptive Facades Network Final Conference; Lucerne University of Applied Sciences and Arts, 2018; pp. 371-377.

[35] Nagy, Z.; Svetozarevic, B.; Jayathissa, P.; Begle, M.; Hofer, J.; Lydon, G.; Willmann, A.; Schlueter, A. The Adaptive Solar Facade: From Concept to Prototypes. Frontiers of Architectural Research 2016, 5, 143-156, doi: 10.1016/j.foar.2016.03.002.

[36] Carl, T.; Schein, M.; Stepper, F. Sun Shades-About Designing Adaptable Solar Facades.; CUMINCAD: Rome, 2017; Vol. 2, pp. 165-174.

[37] Harry, S. Dynamic Adaptive Building Envelopes - an Innovative and State-of-The-Art Technology. Creative Space 2016, 3, 167-184, doi:10.15415/cs.2016.32011.

[38] Wiethoff, A.; Gehring, S. Designing Interaction with Media Façades: A Case Study. In Proceedings of the Proceedings of the Designing Interactive Systems Conference; 2012; pp. 308-317.

[39] Hartkopf, V.; Loftness, V. Global Relevance of Total Building Performance. Automation in Construction 1999, 8, 377-393, doi:10.1016/S0926-5805(98)00085-5.

[40] Kronenburg, R. Flexible: Architecture That Responds to Change; Laurence King, 2007; ISBN 1-85669-461-5.

[41] Shahin, H.S.M. Adaptive Building Envelopes of Multistory Buildings as an Example of High-Performance Building Skins. Alexandria Engineering Journal 2019, 58, 345-352, doi: 10.1016/j.aej.2018.11.013.

[42] Schleicher, S.; Santos, L.; Caldas, L. Data-driven shading systems - Application for freeform glass facades,' in Skins on Campus. Bridging Industry and Academia in Pursuit of Better Buildings and Urban Habitat. Facades Tectonics 2018 World Congress, Tectonic Press, Los Angeles, pp. 3-14.

[43] Hammer, A. Climate Adaptive Building Shells for Plus-Energy-Buildings, Designed on Bionic Principles. International Journal of Architectural and Environmental Engineering 2016, 10, 202-213.

[44] Oral, H.; Karakoç, E. Interactive Structures in Nature 
Inspired Design; In Proceedings of 18th Generative Art Conference, Venice 2015; ISBN 978-88-96610-31-2.

[45] Fox, M. Interactive Architecture: Adaptive World; Chronicle Books, 2016; ISBN 1-61689-511-X.

[46] Fox, M.A.; Yeh, B.P. Intelligent kinetic systems in architecture. In Managing interactions in smart environments; Springer, 2000; pp. 91-103.

[47] Zuk, W.; Clark, R.H. Kinetic Architecture; Van Nostrand Reinhold, 1970; ISBN 978-0-442-15672-5.

[48] Wigginton, M.; Harris, J. Intelligent Skins; Routledge, 2013; ISBN 1-136-39486-9.

[49] Tabadkani, S.; Roetzel, A.; Li, H.X.; Tsangrassoulis, A. A Review of Automatic Control Strategies Based on Simulations for Adaptive Façades. Building and Environment 2020, 175, 1-19, doi: 10.1016/j.buildenv.2020 .106801 .

[50] Luna-Navarro, A.; Loonen, R. C.G.M; Juaristi, M.; Monge-Barrio, A.; Attia, S.; Overend, M. Occupant-Facade Interaction: A Review and Classification Scheme. Building and Environment 2020, 177, 106880, doi: 10.1016/j.buildenv.2020.106880.

[51] Megahed, N.A. An Exploration of the Control Strategies for Responsive Umbrella-like Structures. Indoor and Built Environment 2018, 27, 7-18, doi:10.1177/1420326X16669 750 .

[52] Heidari Matin, N.; Eydgahi, A. Technologies Used in Responsive Facade Systems: A Comparative Study. Intelligent Buildings International 2019, 1-20, doi:10.1080/17508975.2019.1577213.

[53] Turrin, M.; von Buelow, P.; Kilian, A.; Stouffs, R. Performative Skins for Passive Climatic Comfort. Automation in Construction 2012, 22, 36-50, doi: 10.1016/j.autcon.2011.08.001.

[54] Zarzycki, A.; Decker, M. Climate-Adaptive Buildings: Systems and Materials. International Journal of Architectural Computing 2019, 17, 166-184, doi: $10.1177 / 1478077119852707$.

[55] Fernandes, L.L.; Lee, E.S.; Ward, G. Lighting Energy Savings Potential of Split-Pane Electrochromic Windows Controlled for Daylighting with Visual Comfort. Energy and Buildings 2013, 61, 8-20, doi: 10.1016/j.enbuild.2012.10.0 57.

[56] Bakker, L.G.; Brouwer, A.H.M.; Babuška, R. Integrated Predictive Adaptive Control of Heating, Cooling, Ventilation, Daylighting and Electrical Lighting in Buildings. International Journal of Solar Energy 2001, 21, 203-217, doi:10.1080/01425910108914371.

[57] Meerbeek, B.; te Kulve, M.; Gritti, T.; Aarts, M.; van Loenen, E.; Aarts, E. Building Automation and Perceived Control: A Field Study on Motorized Exterior Blinds in Dutch Offices. Building and Environment 2014, 79, 6677doi: 10.1016/j.buildenv.2014.04.023.

[58] Oral, H.; Cağdaş, G. Body Patterning: A Model for Responsive and Interactive Building Envelope. In Proceedings of 17th CAAD Futures Conference, İstanbul,
Turkey; 2017

[59] Okur, Y.; Karakoç, E. Interactive Architecture: The Case Studies on Designing Media Façades; In Proceedings of 22nd Generative Art, Rome, Italy; 2019.

[60] Building Dynamics: Exploring Architecture of Change; Kolarevic, B., Parlac, V., Eds.; Routledge: London; New York, 2015; ISBN 978-1-138-79101-5.

[61] Azar, E.; O’Brien, W.; Carlucci, S.; Hong, T.; Sonta, A.; Kim, J.; Andargie, M.S.; Abuimara, T.; El Asmar, M.; Jain, R.K.; et al. Simulation-Aided Occupant-Centric Building Design: A Critical Review of Tools, Methods, and Applications. Energy and Buildings 2020, 224, 110292, doi: 10.1016/j.enbuild.2020.110292.

[62] Grobman, Y.J.; Yekutiel, T.P. Autonomous Movement Of Kinetic Cladding Components In Building Facades. In ICoRD'13; Springer, 2013; pp. 1051-1061.

[63] Loonen, R.C.G.M.; Favoino, F.; Hensen, J.L.M.; Overend, M. Review of Current Status, Requirements and Opportunities for Building Performance Simulation of Adaptive Facades. Journal of Building Performance Simulation 2017, 10, 205-223, doi:10.1080/19401493.2016 .1152303 .

[64] Chong, A.; Augenbroe, G.; Yan, D. Occupancy Data at Different Spatial Resolutions: Building Energy Performance and Model Calibration. 36.

[65] Moghtadernejad, S.; Mirza, M.S.; Chouinard, L.E. Façade Design Stages: Issues and Considerations. Journal of Architectural Engineering. 2019, 25, doi:10.1061/(ASCE)A E.1943-5568.0000335.

[66] Moghtadernejad, S.; Chouinard, L.E.; Mirza, M.S. Design Strategies Using Multi-Criteria Decision-Making Tools to Enhance the Performance of Building Façades. Journal of Building Engineering 2020, 30, 101274, doi: 10.1016/j.jobe.2020.101274

[67] Ochoa, C.E.; Capeluto, I.G. Strategic Decision-Making for Intelligent Buildings: Comparative Impact of Passive Design Strategies and Active Features in a Hot Climate. Building and Environment 2008, 11.

[68] Drgoňa, J.; Arroyo, J.; Cupeiro Figueroa, I.; Blum, D.; Arendt, K.; Kim, D.; Ollé, E.P.; Oravec, J.; Wetter, M.; Vrabie, D.L.; et al. All You Need to Know about Model Predictive Control for Buildings. Annual Reviews in Control 2020, S1367578820300584, doi: 10.1016/j.arcontrol.2020.0 9.001 .

[69] Böke, J.; Knaack, U.; Hemmerling, M. State-of-the-Art of Intelligent Building Envelopes in the Context of Intelligent Technical Systems. Intelligent Buildings International 2019, $11,27-45$.

[70] Kolarevic, B. Back to the Future: Performative Architecture. International Journal of Architectural Computing 2004, 2, 43-50, doi:10.1260/1478077041220205.

[71] Shandilya, A.; Hauer, M.; Streicher, W. Optimization of Thermal Behavior and Energy Efficiency of a Residential House Using Energy Retrofitting in Different Climates. Civil Engineering and Architecture 2020, 8, 335-349, doi:10.13189/cea.2020.080318. 